\title{
SERÁ POSSÍVEL ACABAR DE UMA VEZ POR TODAS COM O EXÍLIO? "O XALE", DE CYNTHIA OZICK*
}

Max Kohn

Psicanalista, membro do Espace Analytique e da Maison de la Mère et de l'Enfant, em Paris. Diretor de estudos da Universidade de Paris-Diderot Paris 7.

Tradução de Pedro Henrique Bernardes Rondon

RESUMO: O exílio, do francês antigo essil, que provém do latim exsillum, significa a expulsão de alguém de sua pátria, com proibição de retornar. É a obrigação de residir fora de um lugar, longe de uma pessoa cuja ausência é lamentada. No conto “The shawl” [O xale] da escritora norte-americana Cynthia Ozick, o xale do bebê pode ser bebido como um líquido, como se o sujeito fosse uma criança, como se fosse seu próprio filho. Nós não podemos sair de uma vez por todas de nossa condição de infans, aquele que não fala. Não há paraíso perdido do qual estaríamos exilados — nossa infância, por exemplo.

Palavras-chave: Xale, criança, exílio, infantil, pátria.

ABSTRACT: Can we finish with exile? "The shawl” by Cynthia Ozick. Can we finish with exile? Exile, from the old French essil, which comes from the Latin exsillum, means the expelling of someone from his/her homeland and the forbidding to return. It's the enforcement to living out of a place, away from someone whose absence is mourned. In the novel The Shawl, by the American novelist Cynthia Ozick, the baby's shawl can be drunk as if it was liquid, as if one were a baby, one's own child. We cannot leave once and forever our condition of infans, that which doesn't speak. There's no lost paradise from where we were exiled - our childhood, for instance.

Keywords: Shawl, child, exile, infantile, homeland.

$\mathrm{P}$ oderemos acabar com o exílio de uma vez por todas? O exílio, do francês antigo essil, proveniente do latim exsillum, significa a expulsão de alguém de sua pátria, com proibição de retornar; é a obrigação de residir fora de um lugar, longe de uma pessoa cuja ausência é lamentada. No conto The shawl (O xale), da escritora norte-americana Cynthia Ozick, o xale

\footnotetext{
*Intervenção nos encontros “Cartas do exílio”, organizados por Gérard Gourmel, em 27 e 28 de abril de 2007, em Perpignan, França.
} 
do bebê pode ser bebido como um líquido, como se o sujeito fosse uma criança, como se fosse seu próprio filho. O conto de Ozick se baseia no caráter milagroso desse xale de um bebê que Rose, sua mãe, pode beber nas piores condições, num campo de concentração, na ocasião em que a criança morre. O trauma é onipresente, e beber as palavras do Outro não basta. Não podemos sair, de uma vez por todas, de nossa condição de infans, aquele que não fala. Não existe paraíso perdido do qual estaríamos exilados — nossa infância, por exemplo. O infantil em Freud é exatamente tudo aquilo da criança que persiste, insiste, se mantém ou se repete. O infans é falado antes que seja capaz de falar, e disso ele é exilado quando toma a palavra, quando a palavra o toma.

Cynthia Ozick, ensaísta, crítica e romancista, nasceu em 17 de abril de 1928 em New York. É uma das autoras mais conhecidas da literatura judaica norteamericana, e famosa especialmente pelos trabalhos que escreve acerca da vida dos judeus americanos. Busca inspiração em suas origens, na tradição e na história judaica. A autora provém de uma família de emigrantes russos que se refugiaram nos Estados Unidos para escapar dos pogroms. Seus pais se estabeleceram como farmacêuticos no Bronx. Cynthia adquiriu sua vocação de contista ouvindo historietas e as confissões que os clientes vinham contar a sua mãe, "ela era a psicanalista de todo esse mundinho".

Lendo este conto de Cynthia Ozick, uma associação entre a palavra shawl em inglês e Saul, que em iídiche se pronuncia Shoel (ou Shuel, em iídiche polonês), atravessou meu espírito a propósito desse bebê que quer beber o xale da mãe, dessa mãe que bebe o xale da filha quando esta morre na cerca de arame farpado. ${ }^{1}$ Procurei conhecer mais sobre Saul. Ele representa um rei que não é digno de sua função, que é fraco demais, que se esconde de vergonha quando Samuel lhe diz que ele é o novo rei de Israel, e que não cumpre as ordens de Deus quando se trata de exterminar um inimigo do povo judeu como Amalec. Em alemão, der Schal, com um único 'l', é o lenço com que se agasalha o rosto, o lenço de pescoço ou espécie de gravata para mulheres, o véu ou lenço de seda, o xale, e com dois 'l' é der Shall, o som, o barulho, o estrondo, o timbre; e schal é desenxabido, insípido; die Schälung é o ato de descascar. Num artigo sobre o caranguejo, escrito em 1882, Freud considera pela primeira vez o Bau, a construção, a estrutura das fibrilas e das células nervosas nas diferentes espécies animais como sendo schälig, isto é, dissecada, descascada. Mas Der Schall é também “o som”. O Bau, a construção psíquica, é uma estratificação de sons que Freud disseca. Dissequemos o xale.

Saul foi coroado mais ou menos no ano de 1023 antes da era comum, pelo profeta Samuel, de conformidade com os votos do povo. Saul pede a Samuel que

\footnotetext{
1 “Rosa bebeu o xale de Magda até secar" (OZICK, 1990, p.10). (Todas as citações do conto, nas notas deste artigo, estão em inglês no original. N. do T.)
} 
o ajude a recuperar os burros de seu pai, pois estes tinham se extraviado. Esta é uma história curiosa (I Samuel, cap.9). Um homem se apresenta ao maior profeta vivo e pergunta: “Onde está o meu burro?" E o profeta responde: "Ora, teu burro está atrás do alpendre. A propósito, eis que tu és o rei de Israel!" Quando Samuel lhe anuncia que ele será rei, Saul se esconde. Este é um primeiro sinal da fraqueza de seu caráter. O Talmud indica da maneira mais clara que Saul ultrapassa os demais, não apenas no físico, pela altura de sua cabeça e de seus ombros, mas também os ultrapassa moralmente e no plano da ética. É um ser humano exemplar, mas tem uma fraqueza — sofre de uma modéstia deslocada. Uma pessoa realmente humilde reconhece suas verdadeiras forças e suas verdadeiras fraquezas; conhece também a diferença que tem de ser marcada entre a honra que lhe é devida e aquela que cabe à sua função. Entretanto, Saul não é forte o bastante para ser um dirigente do povo judeu. Saul reina de 1023 a 1013 antes da era comum. É rei durante somente dez anos e conhece um final trágico.

De fato, a brevidade de seu reinado é dramática em si, e vai ser provocada pelo erro fatal que logo ele vai cometer. Saul desobedece à ordem de Deus de fazer desaparecer a nação de Amalec. Uma das principais ordens dadas ao povo judeu à sua entrada em Erets-Israel foi a de "fazer desaparecer Amalec" (Deuteronômio $25,19)$. Amalec sempre foi, através de toda a história, o pior inimigo do povo judeu. Simboliza o mal, e a Tora ordena fazê-lo desaparecer da superfície da Terra, porque seu ódio patológico pelos judeus é tão imenso que, se lhe for deixada a oportunidade de fazê-lo, Amalec é que nos faria desaparecer. A máxima ambição de Amalec é livrar o mundo dos judeus e de sua influência moral, e conduzir o planeta de volta à idolatria, ao paganismo e à barbárie, exilar os judeus de uma vez por todas. Visto que se trata de uma guerra cósmica entre o bem e o mal, à qual não é possível dar fim por meio de tratados, Deus ordena aos judeus que destruam Amalec — a nação inteira, até a derradeira cabeça de gado. Saul tem a oportunidade de fazê-lo. Trava o combate, de conformidade com a ordem recebida, contra Amalec, e consegue a vitória; hesita, porém no último momento, quando chega o instante de executar o decreto. Os rebanhos são poupados, e Agag, rei dos Amalecitas, tem sua vida salva também. Agag torna-se pai de uma criança antes de ser morto pelo profeta Samuel, e a nação de Amalec entra numa espécie de clandestinidade. O profeta Samuel anuncia então a Saul:

\footnotetext{
“"Eu não vou voltar contigo, porque tu rejeitaste a palavra de Deus e Deus te declarou indigno de ser o rei de Israel'. E Samuel lhe vira as costas, e ele [Saul], agarra a barra de sua veste que então se rasgou. E Samuel lhe declarou: 'Neste dia Deus te despojou do reino de Israel e o entregou ao teu próximo, que é melhor do que tu'." (I. Samuel 15, 26-28)
} 
Pelo erro assinalado, Saul selou seu destino. Não lhe será dada uma segunda oportunidade. Deus não intervém, porquanto se trata do rei de Israel. Embora Saul tenha perdido seu trono, isso não significa que ele deva ser deposto de imediato. Significa simplesmente que sua linhagem não o sucederá. De fato, após ter feito aquela declaração a Saul, Samuel parte à procura de um outro rei para ungir, e vai encontrá-lo no mais improvável dos lugares.

Voltemos ao conto. A mamãe não tem nada para oferecer à filha, seus seios estão secos, ela também não tem nada para si própria, apenas um xale. ${ }^{2}$

Rosa avança com Magda nos braços, Magda que quer mamar, enrolada num xale, e Stella a acompanha no frio do inferno. Algumas vezes Stella carrega Magda, e ela que tem 14 anos e seios miúdos, tem ciúmes de Magda e de seu xale, no qual ela quer estar enrolada e ela também tem vontade de levar um bebê. No final do conto, ${ }^{3}$ Magda cai junto à cerca de arame farpado eletrificada onde tinha sido assassinada por um guarda, e Rosa não se mexe, não corre, apesar das ordens que recebe, porque de outra maneira eles atirariam nela. Ela apanha o xale de Magda e o traga, ela o bebe, ela sente o gosto da saliva da filha. Esse Shawl, esse xale, nos vem de longe, é uma palavra de origem hindu, shal, ela própria de origem persa, e esse Shawl é Saul, um rei abatido.

No conto, Cynthia Ozick nos fala desse xale, desse grande pedaço de tecido que as mulheres enrolam nos ombros. Rosa se enrola no xale de Magda, invejado por Stella. Ela bebe seu xale até esgotar o cálice da amargura, ela traga Saul, o rei fraco. Magda também bebe o xale, Saul, o rei dos judeus que não os protege de Amalec, seu pior inimigo. Incorporar Saul é uma necessidade para Rosa, Magda e Stella, É o herói do conto, é um nome de rei que não protege de nada, não é um talismã. É um nome-do-pai que não exerce sua função. Rosa, como uma criança, procura em vão beber o tecido, transformar uma matéria sólida

\footnotetext{
2 “Stella, fria, a frieza do Inferno. Como caminharam juntas pelas estradas, Rosa com Magda encolhida entre seus seios feridos, Magda enrolada no xale. Algumas vezes Stella carregava Magda. Mas ela tinha ciúmes de Magda. Uma menina magra de 14 anos, pequena demais, com seus próprios seios finos. Stella queria estar enrolada num xale, escondida dessa maneira, adormecida, embalada pela marcha, um bebê, um bebê gorducho enroscado no colo. Magda pegou o mamilo de Rosa, e Rosa nunca parou de caminhar, um berço andante. Não havia leite suficiente; algumas vezes Magda mamava ar; então gritava. Stella estava faminta. Seus joelhos eram tumores em gravetos, seus cotovelos, ossinhos de galinha” (OZICK, 1990, p. 3).

3 "Magda com alguns ralos cabelos na cabeça raspada, e pernas de lápis e barriga de balão, braços em ziguezague, esborrachada contra a cerca, a voz de aço enlouqueceu em seu rosnado, encorajando Rosa a correr e correr no lugar onde Magda caíra de sua fuga contra a cerca eletrificada; mas Rosa, é claro, não obedeceu. Ela apenas ficou de pé para apanhar os gravetos do corpo de Magda, porque se corresse, eles atirariam, e se ela permitisse que irrompesse o uivo de lobo que agora subia as escadas de seu esqueleto, eles atirariam; assim, ela pegou o xale de Magda e com ele entupiu sua própria boca, enfiou-o e socou-o para dentro, até que estava engolindo o uivo do lobo e sentindo o gosto das profundezas de canela da saliva de Magda, e Rosa bebeu o xale de Magda até que ele secou” (idem, p.10).
} 
em líquido, transformar a própria matéria desse Shawl para que ele não seja Saul. Rosa se estufa com esse xale, esse Shawl, esse Saul.

Rosa Lublin reaparece 30 anos depois num hotel em Miami, louca, e revirando latas de lixo ${ }^{4}$ num outro conto de Cynthia Ozick, “Rosa” (OZICK, 1983/1990). O xale ainda está lá, um xale que pode alimentar uma criança faminta, destruí-la ou magicamente trazê-la de volta à vida. Ela diz uma coisa terrível a Persky, um judeu de Varsóvia que ela conhece, que fala iídiche (o que não é o seu caso), e que quer ter um romance com ela. ${ }^{5}$ Ela lhe diz que só lê literatura em polonês, não em inglês, porque a língua materna é necessária para se ler. ${ }^{6}$

Ela lhe confia que tinha ido passear no quebra-mar porque perdera algo. Persky pergunta o que e ela responde: "a vida". 7

Um pesquisador, James W. Tree, por ocasião de sua estada em Miami, quer estudá-la por causa de sua história nos campos de concentração. ${ }^{8}$ Ela odeia ser considerada uma sobrevivente. ${ }^{9}$ Esse é também o caso de Helen Epstein, que escreveu Le traumatisme en heritage [O trauma por herança] (EPSTEIN, 1979/2005). Helen Epstein escreve: “(...) eu não gostava da maneira como o corpo psiquiátrico tinha descrito os nossos pais” (idem, p.191), e para Deborah, a quem ela deu entrevistas: "A própria ideia de estudos psiquiátricos lhe desagradava muitíssimo” (idem, p.21). Esse é também o horror para Rosa. E o pior, é que ela recebe o xale em seu hotel em Miami. Foi-lhe enviado por Stella, sua sobrinha. ${ }^{10}$ Rosa colocou o xale em cima do telefone e se pôs a falar-lhe, e no momento em que Persky sobe para vê-la, ela o retira dali. Não há Magda, não

\footnotetext{
${ }^{4}$ Em inglês: a madwoman and a scavenger. (N. do T.)

5 "O pai dela, tal como sua mãe, zombava do iídiche; nem a mínima partícula de gueto tinha sobrado nele, nem uma gota de podridão” (OZICK, 1983/1990, p. 21).

6 "Eu só leio em polonês, disse-lhe ela. Não gosto de ler em inglês. Para a literatura você precisa de uma língua materna” (idem, p. 57).

7 "Rosa disse: - Eu estava procurando uma coisa que perdi.

- Pobre Lublin, o que você perdeu?

— A vida." (idem, p. 55)

“- E sem uma vida —, Rosa respondeu — uma pessoa vive onde puder; se não tem nada mais do que seus pensamentos, é aí que eles vivem.

— Você não tem uma vida?

— Os ladrões a levaram." (idem, p. 28-29).

8 "Consequentemente você tem as circunstâncias ideais para contribuir para nosso estudo de R.A. Aguardo ansiosamente seu consentimento na primeira oportunidade”. (idem, p. 38)

9 “Eles não te chamam de mulher, seja como for. 'Sobrevivente'. Mesmo quando os seus ossos ficarem desmanchados nos grãos de terra, eles vão esquecer 'ser humano'. Sobrevivente e sobrevivente e sobrevivente, sempre e sempre.” (idem, p. 36-37)

10 "Na recepção entregaram-lhe um embrulho; desta vez ela examinou a embalagem. Tinha chegado por correio registrado e Stella é quem tinha mandado. Não era possível ser enganada novamente, mas Rosa ficou chocada, esvaziada, quase como se a excitação abrasante de ontem tivesse sido não Tree [O "pesquisador James W. Tree", citado no texto. N. do T.], mas realmente a caixa com o xale de Magda." (idem, p. 62)
} 
há nada. ${ }^{11}$ Não há retorno de Magda. O xale não é Magda. Saul não quer destruir o mal que é Amalec. O xale não apaga o mal: evoca-o. A literatura pode fazer acreditar que é possível sair do exílio, e Cynthia Ozick em particular. Entretanto, o significante transborda infinitamente a letra que procura contê-lo.

Em “Dora”, Rosa encontra Persky numa lavanderia, e quando confere sua roupa, ela se dá conta de que lhe falta uma calcinha. Ela tinha nove delas, e agora só lhe restam oito. ${ }^{12}$ Pant é tempo do verbo to pant — significa ofegar, resfolegar, "arquejar"? 13

Rosa dá pela falta de um underpant, um sopro vindo de baixo, por baixo. Ela arqueja, sopra forte demais, sua vida, sua palavra. Ela não quer ser uma sobrevivente, mas ela é uma sobrevivente, mesmo que isso não queira dizer nada. Ela ainda tem nela o sexual que pode atrair. A prova disso é que ela acredita que quem pegou a calcinha foi Persky, esse maníaco sexual, que ele está com a calcinha no bolso, ${ }^{14}$ esse velho pervertido, e ela pensa até em falar com a esposa dele, porque esta deve conhecer as práticas dele, desse porco. "Her pants in his pants", literalmente isso quer dizer "a calcinha dela na cueca dele", mas essa duplicação remete ao pênis de Persky nas calças dele. Sua calcinha no bolso dele, nas calças dele, esse velho pervertido, e ela pensa mesmo em falar com a esposa dele, porque esta deve conhecer as práticas dele, desse porco. "A calça dela na calça dele", literalmente isso quer dizer "a calcinha dela na cueca dele", “a calça na calça”, mas essa reiteração remete ao pênis de Persky na calça dele. A repetição é intencional, certo? (sim, isso mesmo)A calcinha de Rose a faz escapar ao xale de Magda. Não o duplica num modo perverso. É outra coisa, é sua sexualidade possível. Rose não é Magda. Ela encontra a calcinha dentro de uma toalha. ${ }^{15}$ Ela tinha contado toda uma história com Persky. Magda está morta, ela está viva. O xale não é um fetiche de Magda, como para Rosa uma calcinha poderia ser.

11 "Ela retirou o xale de cima do telefone. Magda não estava ali. Encabulada, ela fugiu de Persky. Magda estava longe.” (idem, p. 70)

12 "Estava faltando uma calcinha. Uma vez mais Rosa contou tudo: quatro blusas, três saias de algodão, três sutiãs, um biquíni, uma calcinha comum, duas toalhas, oito calcinhas... tinham ido nove para a máquina de lavar, esse o número exato." (idem, p. 33)

13 Em toda esta passagem há um jogo de palavras entre pant (calça) e to pant (resfolegar, arquejar, respirar com dificuldade), underpant (roupa de baixo, calcinha/cueca) e underpant (um sopro de baixo, por baixo). (N. do T.)

14 "Então lhe ocorreu que Persky estava com a calcinha no bolso... E o que aconteceria quando ele chegasse em casa com a calcinha dela? O que é que um homem, meio-viúvo, havia de fazer com uma calcinha de mulher?... A esposa dele confessaria quais os hábitos sexuais de Persky." (idem, p. 54)

15 "De manhã, ao lavar o rosto - que estava inchado, pesadelos como ervas daninhas, a ponta do nariz pálida - Rosa encontrou a calcinha que faltava, embolada dentro de uma toalha." (idem, p. 61). 
E eis que Rose sai em busca de sua calcinha, agora que estamos no trágico da evocação de Magda com seu xale. Retalhos de pano circulam e se cruzam. O xale é mesmo apontado por Stella como um ídolo. ${ }^{16}$ A calcinha e o xale estão presentes, em parte, num modo perverso.

Uma letra pode deixar sem voz. Para Jean-Toussaint Desanti (DESANTI, 1999, p.64-65), o Outro é texto, e a literatura dá testemunho do excesso do significante sobre ela. A literatura não chega a fixar limites para o significante. Há um excesso de coisas em relação a todas as suas expressões, e um excesso das coisas em relação às palavras. O corpo do autor está ausente do texto, ausência essencial do Outro que remete a um sujeito que não é mais do que o vazio onde ele deve se mostrar, não existindo senão em suspenso, quer ele persista ou se destitua. O texto é um entremeio da presença e da ausência. Um texto se basta e se dirige a si mesmo como outro. Aquele que o aborda é confrontado a um efeito de exclusão. Dizer “isto é o meu texto”, é propriamente enigmático.

Anne-Lise Stern, em sua reflexão sobre “o xale”, nos dá outra pista, mas ela não faz a associação entre Saul e shawl. Em Le Savoir Déporté, Anne-Lise Stern analisa o conto de Cynthia Ozick. E aí fala do farrapo que o sobrevivente tinha sido no campo: "Quando ele fala, trata-se sempre do farrapo que ele tinha sido, que tinham sido os outros à volta dele” (STERN, 1998, p.61). Em “O xale”, ela escreve: "Fui ao mesmo tempo Magda, Stella, Rosa" (idem, 2004, p.197-200). Foi uma analisanda que lhe ofereceu o texto. Já era objeto de uma transmissão. ${ }^{17}$ E ela acrescenta: "Na repentina separação daqueles que nos são próximos e dos lugares-tenentes-de-objeto, o único objeto que nos restava era esse corpo, que era nós, esse corpo de nada em que nos tornávamos. Como Rosa no livro, como Magda, eu não admito que toquem no meu xale” (idem, p.200). Ela fica deitada de lado, encolhida, no Revier, o hospital do campo de Auschwitz, apesar do risco de ser selecionada para ser mandada para a câmara de gás, por não ir ao trabalho, ao abrigo de suas próprias costas "maternalmente curvada à minha volta. Quando não delirava, eu pensava: é preciso que eu lhes entregue de volta. Eu devia entregar de volta à minha mãe aquilo que me restava do pedaço que eu tinha dela, da carne de sua carne. Eu sentia isso como um verdadeiro dever" (loc. cit.). E mais: "Meu xale é o objeto a elaborado por Lacan a partir daquilo que lhe tinha sido trazido de volta de lá, mas também da casa dos doutores Buisson" (loc. cit.). Sobre isso ela chega mesmo a afirmar que o pequeno a da teorização lacaniana, o obscuro objeto do desejo, vem de Auschwitz. Retomando aquilo que Lacan diz "Só os deportados participam da história: uma vez que o homem tem um corpo, é pelo corpo que se tem o homem. É o avesso do habeas corpus”

16 "Está certo, eu fiz isso. Fui ao correio e despachei-o. O seu ídolo está a caminho, num embrulho separado." (idem, p. 31)

${ }^{17}$ Aliás, eu ouvira falar desse livro por meus alunos, e por minha esposa Nelly. 
(loc. cit.). E ela conclui: “Na repentina separação daqueles que nos são próximos e dos lugares-tenentes-de-objeto, o único objeto que nos restava era esse corpo que era nós, esse corpo de nada em que nos tornávamos” (loc. cit.).

Vamos terminar com uma história traduzida do iídiche.

\section{Adão e Eva}

Shayndl: - Adão e Eva tiveram a melhor vida de casal.

Krayndl: — Como é que você sabe?

Shayndl: - Porque Eva não podia falar com ele sobre os homens melhores (mer gerotene) que queriam se casar com ela. E Adão não podia dizer a ela como a mãe dele cozinhava bem.

Geroten significa "bom”, "bem-sucedido”, e a historieta joga com o equívoco, uma vez que literalmente isso quer dizer que teria podido haver aí homens melhores - melhores partidos para Eva. Mas um homem notável em seu gênero não é um homem que se saiu bem. Deus desperdiçou sua criação. O homem se torna mau ao comer o fruto da árvore do conhecimento. Deus o manda para o exílio. Adão não pode falar dos quitutes (OK) que sua mãe cozinhava. Adão e Eva estão sozinhos no Paraíso, e Eva não pode falar de outros homens que a desejariam. Não havia nenhum. Adão também não pode ser sacudido por seu desejo por várias mulheres. O mito do casal originário é verdadeiramente um mito. O Paraíso é um inferno. É preciso sair daí para desejar o Outro. Viva o exílio! Viva a literatura que é testemunha disso! Esse não é um êxito, mas sim um fracasso. Nossa vida cotidiana — e não existe outra — não é nem um paraíso nem um inferno. Podemos achar desejável que nossa mulher seja cobiçada por outros homens, e podemos deleitar-nos de pensar nos quitutes que nossa mãe fazia - mais até, aliás, do que nas outras mulheres que poderíamos possuir. Para um homem, pensar em sua mãe e, para uma mulher, pensar em outros homens, não é tão mau. Ela então não pensa em seu pai.

Um lugar onde não há nem pai, nem mãe, nem filho, nem outros homens, nem outras mulheres - o paraíso de Adão e Eva - é terrível. Parem de querer o paraíso que não existe, e de considerar que a vida de vocês é um inferno. Vocês não sabem a sorte que têm. Seu marido pensa mais na mãe dele do que em você, e você, você pensa mais nos outros homens do que nele. Seu pai não está muito presente na história, porque ele não é Deus, e não é tão mau para uma mulher dizer que seu pai não é Deus, e que há outros homens. Não é tão mau para um homem dizer que os pratos que sua mulher prepara para ele não são tão bons quanto aqueles que sua mamãe fazia. Ele lamenta a ausência de sua mãe, e pode investir em sua mulher. É preciso se haver com aquilo que se tem, e não ficar lamentando sei lá qual paraíso perdido, e tornar nosso cotidiano ainda 
mais infernal. Em todo caso, enquanto há desejo, há esperança. Não fiquem sonhando com o paraíso. Vivam suas vidas de casal aqui e agora, com todas as suas insatisfações, e desejem o próprio exílio.

Não se pode ficar suspirando pelo paraíso, sentindo-se exilado dele. Adão e Eva deviam ir muito mal. Não sabemos como as coisas começaram. É preciso poder retornar ao ponto de partida incessantemente, e partir outra vez em novas bases, mas a origem está perdida. O paraíso está perdido. O paraíso nunca existiu. Não há senão este mundo, e não podemos acabar de uma vez por todas com o exílio onde ele nos põe desde sua origem, desde sua cena primitiva. Podemos exatamente imaginar aquilo que quisermos acerca do início e do fim, e podemos beber o xale do bebê que somos. O exílio é nosso mundo. É nosso estado, como pensa Walter Benjamin. Mas devemos aprender a desejá-lo, e não sofrer esse estado como uma opressão, como a etimologia indica. O desejo de exílio é nosso mundo.

Recebido em 10/12/2007. Aprovado em 6/2/2008.

\section{REFERÊNCIASS}

DESANTI, J.-T. (1999) Philosophie: um rêve de flambeur, Variations philosophiques 2. Conversations avec Dominique Grisoni. Paris: Bernard Grasset.

EPSTEIN, H. (1979/2005) Le traumatisme en héritage. Paris: La Cause des Livres.

FREUD, S. (1882) “Ueber den Ban der Nervenfasern und Nervenzellen beim Flusskrebs”. Aus dem LXXXV Band (vol) der Sitzungberichte der keiserlichen Akademie der Wissenschaft in Wien, Mathematisch-naturwissenschaftlichen Klasse. I. Abt, Wien, (Jänner), p.9-46.

KOHN, M. (1982/2005) Freud et le Yiddish: le préanalytique (1877-1897). Paris: Anthropos Economica, p.109-110. Tradução no Brasil Freud e 0 iídiche, por M. Mortara. Rio de Janeiro: Imago, 1994.

OZICK, C. (1983) “Rosa”, in The Shawl. New York: Vintage Books, a division of Random House, Inc., p.11-70.

(1989) “Le Châle”, Paris: Éd. de l'Olivier.

(1990) “The Shawl”, in The Shawl. New York: Vintage Books, a division of Random House, Inc., p.3-10.

STERN, A.-L. (1998) “Um lieu por le dire”. L’Infini, n. 61, primavera. (2004) “Le Châle”, in Le Savoir Déporté. Camps, histoire, psychanalyse. Paris: Seuil. 